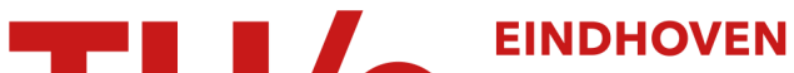 UNIVERSITY OF TECHNOLOGY
}

\section{Proof of a conjecture on the supports of Wigner distributions}

Citation for published version (APA):

Janssen, A. J. E. M. (1998). Proof of a conjecture on the supports of Wigner distributions. Journal of Fourier Analysis and Applications, 4(6), 723-726. https://doi.org/10.1007/BF02479675

DOI:

10.1007/BF02479675

Document status and date:

Published: 01/01/1998

\section{Document Version:}

Publisher's PDF, also known as Version of Record (includes final page, issue and volume numbers)

\section{Please check the document version of this publication:}

- A submitted manuscript is the version of the article upon submission and before peer-review. There can be important differences between the submitted version and the official published version of record. People interested in the research are advised to contact the author for the final version of the publication, or visit the $\mathrm{DOI}$ to the publisher's website.

- The final author version and the galley proof are versions of the publication after peer review.

- The final published version features the final layout of the paper including the volume, issue and page numbers.

Link to publication

\section{General rights}

Copyright and moral rights for the publications made accessible in the public portal are retained by the authors and/or other copyright owners and it is a condition of accessing publications that users recognise and abide by the legal requirements associated with these rights.

- Users may download and print one copy of any publication from the public portal for the purpose of private study or research.

- You may not further distribute the material or use it for any profit-making activity or commercial gain

- You may freely distribute the URL identifying the publication in the public portal.

If the publication is distributed under the terms of Article 25fa of the Dutch Copyright Act, indicated by the "Taverne" license above, please follow below link for the End User Agreement:

www.tue.nl/taverne

Take down policy

If you believe that this document breaches copyright please contact us at:

openaccess@tue.nl

providing details and we will investigate your claim. 


\title{
Proof of a Conjecture on the Supports of Wigner Distributions
}

\author{
A.J.E.M. Janssen \\ Communicated by John J. Benedetto
}

ABSTRACT. In this note we prove that the Wigner distribution of an $f \in L^{2}\left(\mathbb{R}^{n}\right)$ cannot be supported by a set of finite measure in $\mathbb{R}^{2 n}$ unless $f=0$. We prove a corresponding statement for cross-ambiguity functions. As a strengthening of the conjecture we show that for an $f \in L^{2}\left(\mathbb{R}^{n}\right)$ its Wigner distribution has a support of measure 0 or $\infty$ in any half-space of $\mathbb{R}^{2 n}$.

\section{Introduction}

Benedicks [1] has shown that when $f \in L^{1}\left(\mathbb{R}^{n}\right)$ satisfies

$$
|\Sigma(f)||\Sigma(\hat{f})|<\infty,
$$

then $f=0$. Here $\Sigma(f)$ is the set $\{x \mid f(x) \neq 0\}, \Sigma(\hat{f})$ is the set $\{y \mid \hat{f}(y) \neq 0\}$ with

$$
\hat{f}(y)=(\mathcal{F} f)(y)=\int e^{-2 \pi i x \cdot y} f(x) d x, \quad y \in \mathbb{R}^{n},
$$

the Fourier transform of $f$, and || denotes Lebesgue measure. We refer to [2, Section 7], for historical notes and further comments on this theorem.

It is conjectured in $\left[2\right.$, Section 7], that when $f \in L^{2}\left(\mathbb{R}^{n}\right)$ and $|\Sigma(W(f, f))|<\infty$, then $f=0$. Here

$$
\Sigma(W(f, f))=\left\{(t, v) \in \mathbb{R}^{2 n} \mid W(f, f)(t, v) \neq 0\right\},
$$

and $W(f, f)$ is the Wigner distribution of $f$. When $f, g \in L^{2}\left(\mathbb{R}^{n}\right)$, we define the Wigner transform of $f$ and $g$ as

$$
W(f, g)(t, v)=\int e^{-2 \pi i v \cdot x} f\left(t+\frac{1}{2} x\right) g^{*}\left(t-\frac{1}{2} x\right) d x, \quad t, v \in \mathbb{R}^{n}
$$

Math Subject Classifications. 42B10, 94A12.

Keywords and Phrases. Uncertainty principle, Wigner distribution, ambiguity function. 
and when $f=g$ in (1.4), we speak of the Wigner distribution of $f$. We refer to [2, Section 6], and [3, Ch. 1, Sections 4, 8], for more information on Wigner distributions, and to [2, Section 7], for some partial results regarding the conjecture. The author was kindly informed by Folland that the conjecture occurred during discussions between Mustard and Sitaram who noticed, for instance, that one must have $\left|\sum(W(f, f))\right|=\infty$ when $f \in L^{2}\left(\mathbb{R}^{n}\right)$ is even or odd. It was furthermore observed by Mustard, see [2, Section 7], that (as $W(f, f) \in L^{1}\left(\mathbb{R}^{2 n}\right)$ when $f \in L^{2}\left(\mathbb{R}^{n}\right)$ and $\left.|\Sigma(W(f, f))|<\infty\right)$ one could use Benedicks' theorem with $f \in L^{1}\left(\mathbb{R}^{n}\right)$ replaced by $W(f, f) \in L^{1}\left(\mathbb{R}^{2 n}\right)$ once one would know that $|\Sigma(\mathcal{F}(W(f, f)))|<\infty$ as well.

\section{Proof of the Conjecture}

We shall now present a proof of the conjecture. It is based on the following formula,

$$
\begin{aligned}
\iint W\left(f_{1}, f_{2}\right)(t, v) W^{*}\left(g_{1}, g_{2}\right)(s-t, \mu-v) e^{-2 \pi i a \cdot t+2 \pi i b \cdot v} d t d v \\
=\frac{1}{4^{n}} e^{-\pi i a \cdot s+\pi i b \cdot \mu} W\left(f_{1}, g_{1}\right)\left(\frac{1}{2} s+\frac{1}{4} b, \frac{1}{2} \mu+\frac{1}{4} a\right) \\
W^{*}\left(f_{2}, g_{2}\right)\left(\frac{1}{2} s-\frac{1}{4} b, \frac{1}{2} \mu-\frac{1}{4} a\right),
\end{aligned}
$$

valid for $f_{1}, f_{2}, g_{1}, g_{2} \in L^{2}\left(\mathbb{R}^{n}\right)$ and $s, \mu, a, b \in \mathbb{R}^{n}$. This formula, see Section 3, is a straightforward consequence of Moyal's formula, see [3, Ch. 1, Section 8, (1.93)], and a special case, viz. where $f_{1}=f_{2}=g_{1}=g_{2}$ and $a=b=0$, has been used already in [4, Section 6, (75)], to study the interference phenomena present in Wigner distributions. Also, formula (2.1) can be regarded as a generalization of Siebert's self-transform property [5] for ambiguity functions, see (2.4) and (2.5) below, for which the choice $f_{1}=g_{2}=f, f_{2}=g_{1}=\tilde{f}, s=\mu=0$ must be made. Formula (2.1) was found by Hlawatsch in 1986 , see [6,7], formula (7.77-78) and also [8], and, independently, by Nuttall in 1989 [9].

To prove the conjecture, we let $s, \mu \in \mathbb{R}^{n}$ be fixed, and we choose $f_{1}=f_{2}=g_{1}=g_{2}=f \in$ $L^{2}\left(\mathbb{R}^{n}\right)$ in $(2.1)$, so that

$$
\begin{gathered}
\iint W(f, f)(t, \nu) W^{*}(f, f)(s-t, \mu-\nu) e^{-2 \pi i a \cdot t+2 \pi i b \cdot \nu} d t d \nu \\
=\frac{1}{4^{n}} e^{-\pi i a \cdot s+\pi i b \cdot \mu} W(f, f)\left(\frac{1}{2} s+\frac{1}{4} b, \frac{1}{2} \mu+\frac{1}{4} a\right) \\
W^{*}(f, f)\left(\frac{1}{2} s-\frac{1}{4} b, \frac{1}{2} \mu-\frac{1}{4} a\right)
\end{gathered}
$$

for all $a, b \in \mathbb{R}^{n}$. The function

$$
\chi(t, v)=W(f, f)(t, v) W^{*}(f, f)(s-t, \mu-\nu), \quad t, v \in \mathbb{R}^{n},
$$

which is in $L^{1}\left(\mathbb{R}^{2 n}\right)$ since $W(f, f) \in L^{2}\left(\mathbb{R}^{2 n}\right)$, has a support of finite measure when $|\Sigma(W(f, f))|<$ $\infty$, and so has its Fourier transform as we see from (2.2). Hence, Benedicks' theorem yields that $\chi=0$. Since $s, \mu \in \mathbb{R}^{n}$ are arbitrary, it follows easily that $W(f, f)=0$, i.e., $f=0$. by

When we take $f, g \in L^{2}\left(\mathbb{R}^{n}\right)$, and we define the cross-ambiguity function $A(f, g)$ of $f$ and $g$

$$
A(f, g)(p, q)=\int e^{2 \pi i q \cdot y} f\left(y+\frac{1}{2} p\right) g^{*}\left(y-\frac{1}{2} p\right) d y, \quad p, q \in \mathbb{R}^{n}
$$


then it follows in a similar fashion that $f=0$ or $g=0$ whenever $|\Sigma(A(f, g))|<\infty$. For this we use the fact

$$
W(f, \tilde{g})(u, v)=2^{n} A(f, g)(2 u, 2 v)=W^{*}(\tilde{g}, f)(u, v),
$$

valid for all $u, v \in \mathbb{R}^{n}$, where we have set $\tilde{g}(x)=g(-x), x \in \mathbb{R}^{n}$, together with formula (2.1) in which $f_{1}=g_{2}=f, f_{2}=g_{1}=\tilde{g}$ is taken, to conclude that $A(f, g)=0$ whenever $|\Sigma(A(f, g))|<$ $\infty$. Since $A(f, g)=0$ if and only if $f=0$ or $g=0$ we get the result. Obviously, we now also have that $f \in L^{2}(\mathbb{R})$ is the null function whenever its short-time Fourier transform $S_{g} f=|A(f, g)|^{2}$, using a window $0 \neq g \in L^{2}(\mathbb{R})$, vanishes outside a set of finite measure.

The argument used to prove the conjecture gives somewhat more. The extension of the conjecture given below is significant since it shows, for instance, that supporting sets of Wigner distributions cannot have finite-measure protrusions.

Corollary 1.

Assume that $f \in L^{2}\left(\mathbb{R}^{n}\right)$, and let $H$ be any half-space in $\mathbb{R}^{2 n}$. Then

$$
|\{(t, \nu) \in H \mid W(f, f)(t, \nu) \neq 0\}|=0 \text { or } \infty .
$$

Proof. We start by noting that we can write (2.2) as

$$
\left(\mathcal{F}_{t} \mathcal{F}_{\nu} \chi\right)(a,-b)=\frac{1}{4^{n}}, e^{-\pi i a \cdot s+\pi i b \cdot \mu} \chi\left(\frac{1}{2} s+\frac{1}{4} b, \frac{1}{2} \mu+\frac{1}{4} a\right)
$$

with $\chi$ given for $s, \mu \in \mathbb{R}^{n}$ by (2.3) and $\mathcal{F}_{t}, \mathcal{F}_{v}$ denoting Fourier transforms with respect to the respective variables. by

By using symplectic transformations, see [3, Ch. 4, Section 2], we can assume that $H$ is given

$$
H=\left\{(t, v) \mid t=\left(t_{1}, \ldots, t_{n}\right) \in \mathbb{R}^{n}, t_{1}<0, v \in \mathbb{R}^{n}\right\} .
$$

Suppose that the set in (2.6) with $H$ in (2.8) has finite measure; we must show that it has measure 0 . For any $s=\left(s_{1}, \ldots, s_{n}\right) \in \mathbb{R}^{n}, s_{1}<0, \mu \in \mathbb{R}^{n}$ we have that $\chi$ of (2.3) has support of finite measure since at least one of $t_{1}$ and $s_{1}{ }^{\prime}-t_{1}$ is negative when $t_{1} \in \mathbb{R}$. Hence, (2.7) and Benedicks' theorem yields that

$$
W(f, f)(t, v) W^{*}(f, f)(s-t, \mu-v)=0, \quad t, v \in \mathbb{R}^{n},
$$

with arbitrary $s=\left(s_{1}, \ldots, s_{n}\right) \in \mathbb{R}^{n}, s_{1}<0, \mu \in \mathbb{R}^{n}$. Now when $(t, v) \in H$, we use (2.9) with $s=2 t, \mu=2 \nu$ to conclude that $W(f, f)(t, \nu)=0$. Hence, $W(f, f)$ vanishes on $H$, as required.

We finally note that the Corollary remains valid, with essentially the same proof using (2.5), when we replace $W(f, f)$ by $A(f, g)$ in (2.6) with $g \in L^{2}\left(\mathbb{R}^{n}\right)$.

\section{Proof of Formula (2.1)}

For $f \in L^{2}\left(\mathbb{R}^{n}\right), x \in \mathbb{R}^{n}, y \in \mathbb{R}^{n}$ we let

$$
f_{x, y}(t)=e^{2 \pi i y \cdot t} f(t-x), \quad t \in \mathbb{R}^{n} .
$$

Now when $s, t, \mu, \nu, a, b \in \mathbb{R}^{n}$ and $g_{1}, g_{2} \in L^{2}\left(\mathbb{R}^{n}\right)$, we have

$$
W\left(g_{1}, g_{2}\right)(s-t, \mu-v) e^{2 \pi i a \cdot t-2 \pi i b \cdot v}=W\left(h_{1}, h_{2}\right)(t, v),
$$

where

$$
h_{1}=\left(\left(\tilde{g}_{1}\right)_{s, \mu}\right)_{\frac{1}{2} b, \frac{1}{2} a}, \quad h_{2}=\left(\left(\tilde{g}_{2}\right)_{s, \mu}\right)_{-\frac{1}{2} b,-\frac{1}{2} a} .
$$


Hence Moyal's formula, see [3, Ch. 1, Section 8, (1.93)],

$$
\begin{aligned}
& \iint W\left(f_{1}, f_{2}\right)(t, v) W^{*}\left(h_{1}, h_{2}\right)(t, v) d t d v \\
& =\left(\int f_{1}(x) h_{1}^{*}(x) d x\right)\left(\int f_{2}(y) h_{2}^{*}(y) d y\right)^{*},
\end{aligned}
$$

yields formula (2.1) on using

$$
\begin{aligned}
& \int f_{1}(x) h_{1}^{*}(x) d x \\
& =\left(\frac{1}{2} \pi\right)^{n} e^{\frac{1}{2} \pi i \mu \cdot b-\pi i \mu \cdot s-\frac{1}{4} \pi i a \cdot b-\frac{1}{2} \pi i a \cdot s} W\left(f_{1}, g_{1}\right)\left(\frac{1}{2} s+\frac{1}{4} b, \frac{1}{2} \mu+\frac{1}{4} a\right)
\end{aligned}
$$

and a similar formula for the second factor at the right-hand side of (3.4).

Note added in proof. The author was kindly informed by Prof. G.B. Folland that Dr. P. Jaming and Dr. E. Wilczok have obtained proofs, independently of one another and of the author, of the Mustard-Sitaram conjecture (to appear in C.R. Acad. Sci. Paris Series 1, Vol. 399, 1998) and of the result on the short-time Fourier transform proved in Sec. 2 (in E. Wilczok, Thesis, "Zur Funktionalanalysis der Wavelet- und Gabortransformation," TU Muenchen, 1998), respectively.

\section{References}

[1] Benedicks, M. (1985). On Fourier transforms of functions supported on sets of finite Lebesgue measure, J. Math. Anal. Appl., 106, 180-183.

[2] Folland, G.B. and Sitaram, A. (1997). The uncertainty principle: a mathematical survey, J. Fourier Anal. Appl., 3, 207-238.

[3] Folland, G.B. (1989). Harmonic Analysis in Phase Space, Princeton University Press, Princeton, NJ.

[4] Janssen, A.J.E.M. (1982). On the locus and spread of pseudo-density functions in the time-frequency plane, Philips J. Res., 37, 79-110.

[5] Siebert, W.M. (1958). Studies of Woodward's uncertainty function, Quarterly Progress Report, Electronics Research Lab., M.I.T., Cambridge, MA., April 15, 90-94.

[6] Hlawatsch, F. (1986). Notes on bilinear time-frequency signal representations, Technical Report, Institut für Nachrichtentechnik und Hochfrequenztechnik, TU Wien, Vienna, Austria, December.

[7] Hlawatsch, F. (1988). A study of bilinear time-frequency signal representations, with applications to timefrequency signal synthesis, Ph.D. thesis, TU Wien, Vienna, Austria, May.

[8] Hlawatsch, F. (1992). Regularity and unitarity of bilinear time-frequency signal representations, IEEE Trans. Inform. Theory, 38, 82-94.

[9] Nuttall, A.H. (1990). Two-dimensional convolutions, correlations, and Fourier transforms of combinations of Wigner distribution functions and complex ambiguity functions, NUSC Technical Report 8759.

Received July 14, 1997

Revision received October 1,1997

Philips Research Laboratories, 5656 AA Eindhoven, The Netherlands e-mail: janssena@natlab.research.philips.com 